\title{
Prevalence and Risk Factors of Work-Related Musculoskeletal Disorders among Nurses in Erbil Teaching Hospitals
}

Salih Ahmed Abdulla; Department of Nursing, College of Nursing, Hawler Medical University, Erbil, Iraq. (Correspondence: salih.ahmed@nur.hmu.edu.krd)

\begin{abstract}
Background and objective: The term musculoskeletal disorders includes a gamut of inflammatory and degenerative conditions that affect the muscles, tendons, ligaments, joints, peripheral nerves, and supporting blood vessels with consequent ache, pain or discomfort. The risk of musculoskeletal disorders is high among various healthcare professionals. This study investigated the prevalence of work-related musculoskeletal disorders and risk factors among nurses in Erbil teaching hospitals.

Methods: This cross-sectional study was conducted in Erbil city teaching hospitals in the Kurdistan Region of Iraq. A total number of 256 nurses were selected as study samples through the use of non-probability convenience sampling method. The data were collected by a standardized questionnaire through the use of the interview (face to face) technique.

Results: The previous 12-month prevalence of work-related musculoskeletal disorders among nurses was $67 \%$. Lower back disorder was the most prevalent disorder compared to other body regions at $75 \%$ followed by $52 \%$ reported in one or both knees, and the lowest percentages (9\%) reported in the upper back region.

Conclusion: Work-related musculoskeletal disorders are high among nurses. There was an association between the prevalence of musculoskeletal disorders, genders, and training program on preventing work-related musculoskeletal disorders. It is recommended that training programmes on prevent work-related musculoskeletal disorders be implemented for all nurses.
\end{abstract}

Keywords: Musculoskeletal disorders; Work-related musculoskeletal disorders; Erbil; Low back disorder.

\section{INTRODUCTION}

Work-related musculoskeletal disorders (WMSDs) are isolated or shared problems in the muscles, tendons, synovial membranes (joint tissue) nerves, fascia (connective tissue) and ligaments, with or without tissue degeneration. They are diagnosed by the occurrence of symptoms, along with or not, like: pain, numbness, feeling of heaviness and fatigue [1]. These injuries generally affect the superior limbs, scapular region around the shoulder and cervical region, but can also affect the inferior limbs and are frequent causes of temporary or permanent occupational disabilities. Injury caused by work-related musculoskeletal disorders arise from the extreme use of the musculoskeletal system and its inadequate recovery, and comprises clinical conditions. Workers are victims when they are submitted to poor work conditions [2]. The risk of work-related musculoskeletal disorders is high among different healthcare professionals [3]. WMSDs happen in some careers, including nursing, 
three or four times more often than in the general population [4].Nurses are at risk of WMSDs due to their employment. Hospital nursing tasks are generally composite and involve many physical activities that can lead to acute and chronic work related musculoskeletal disorders[5].The main risk factors related to WMSDs among nurses are extended hours of standing in the operation theatre; carrying and transporting patients; awkward posture; working without adequate breaks; numerous forward bending for dressing patients, I.V line insertions, and giving injections; and carrying heavy weights[4,6]. Demographic characteristics and psychosocial factors such as age, gender, physical status, smoking, and workplace stress are also known to be important predictive variables[7].Decreasing risk factors is an important component of both treatment and prevention. However, the effects of rest time and physical activities on musculoskeletal symptoms and disability in worker populations have showed inconsistent results [8].

This study investigated the prevalence and risk factors of work-related musculoskeletal disorders (WMSDs) among nurses in Erbil teaching hospitals.

\section{METHODS}

The design of the study was quantitative cross sectional. It was conducted in the Erbil city teaching hospitals in the Kurdistan Region of Iraq. The hospitals included: Hawler teaching hospital, Rizgary teaching hospital, Maternity and Delivery teaching hospital, Raparin paediatric teaching hospital, and the Surgical Specialty teaching hospital/Cardiac Centre. All of the nurses of the teaching hospitals who met the inclusion and exclusion criteria were the population of this study. Two hundred and fifty six nurses were selected as samples from different units and wards and from different work shifts in the five hospitals.
Non-probability convenience sampling technique (also called accidental sampling) was used according to the following inclusion criteria: nurses who worked on all shifts according to the policy of the hospitals, nurses who work on different units and wards, both genders, and all categories of nurses (e.g. nursing school graduate, preparatory nursing graduate, institutional graduates and post graduates). Data were collected through interviews by using a standardized questionnaire called the standardized Nordic Questionnaire for Musculoskeletal Symptoms [9]. The data gathered from the nurses at their work places did not affecting on their duties during the interview time. Each nurse's interview took 10-15 minutes. The researcher gave examples when needed but did not assist in answering the questionnaire. The nurses' agreement for participation in the study was obtained and the interview was carried out individually. The reliability of the Standardized Nordic Questionnaire for Musculoskeletal Symptoms has been confirmed in various studies. Dawson et al. (2009) reported that the Questionnaire had demonstrated reliability results Kappa values ranging from 0.88 to 1 , and this questionnaire has been internationally validated. The data were analyzed with Statistical Package for Social Sciences (SPSS) version 21. Frequencies, Chi square test and Fisher exact test were used for interpretation of the data. The probability values greater than 0.05 were considered statistically insignificant throughout the analysis.

\section{RESULTS}

Figure 1 shows the prevalence of work related musculoskeletal disorders among nurses in Erbil teaching hospitals. The highest number of nurses who demonstrated WMSDs was 175 (66.8\%). Table 1 shows the work-related musculoskeletal disorders (WMSDs) experienced per each body 
region in the past twelve months. Lower back disorder was reported by three quarters $(75 \%)$ of the study sample, followed by $52 \%$ disorders reported in one or both knees. The lowest percentage $(9 \%)$ of disorders was reported in the upper back region.

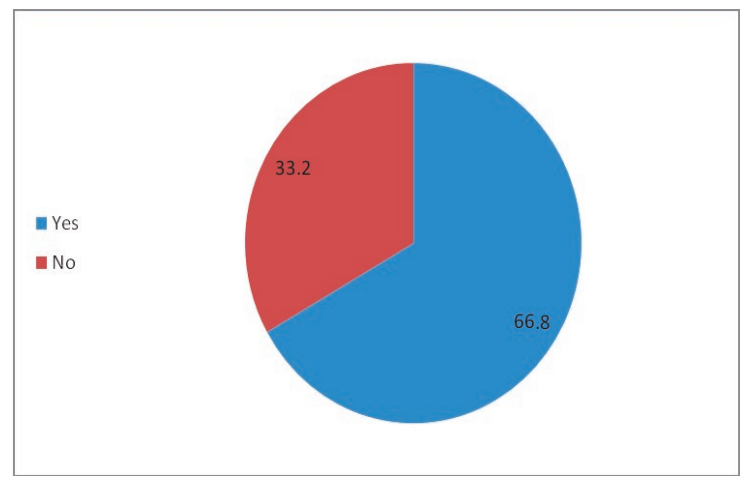

Figure 1: Prevalence of the Musculoskeletal Disorders (MSDs) among nurses quarter (28.6\%) had BMI between 25-29.9 (overweight); and $45 \%$ did not do regular physical exercise in comparison to the nurses who had WMSDs were performed regular physical exercise (21.8\%). The table also show that there is significant association between the prevalence of WMSDs among nurses and gender ( $p$-value $=0.05$ ). The results show that there is no significant relationship between marital status and prevalence of WMSDs. Data analysis also shows that there is no significant association between the prevalence of WMSDs among participant nurses and variables of smoking, exercise and BMI ( $p$-value $=0.05$ ). Table 3 shows that $31.7 \%$ of the nurses who had WMSDs had between 1-10 years' experience in nursing, near to one fifth $(19.8 \%)$ of them work in surgical ward, near to half (49.2\%) were not having

Table 1: Prevalence of the WMSDs by the body regions

\begin{tabular}{lcccccc}
\hline \multirow{2}{*}{ Body regions } & \multicolumn{2}{c}{ Yes } & \multicolumn{2}{c}{ No } & \multicolumn{2}{c}{ Total } \\
\cline { 2 - 7 } & $\mathbf{F}$ & $\mathbf{( \% )}$ & $\mathbf{F}$ & $\mathbf{( \% )}$ & $\mathbf{F}$ & $\mathbf{( \% )}$ \\
\hline Neck & 80 & $(46)$ & 95 & $(54)$ & 175 & $(100)$ \\
Shoulders & 69 & $(39)$ & 106 & $(61)$ & 175 & $(100)$ \\
Elbows & 22 & $(13)$ & 153 & $(87)$ & 175 & $(100)$ \\
Wrists/ Hands & 63 & $(36)$ & 112 & $(64)$ & 175 & $(100)$ \\
Upper back & 16 & $(9)$ & 159 & $(91)$ & 175 & $(100)$ \\
Lower back & 131 & $(75)$ & 44 & $(25)$ & 175 & $(100)$ \\
One or both Hips/Thighs & 52 & $(30)$ & 123 & $(70)$ & 175 & $(100)$ \\
One or both Knees & 91 & $(52)$ & 84 & $(48)$ & 175 & $(100)$ \\
One or both Ankles/ Feet & 20 & $(11)$ & 155 & $(89)$ & 175 & $(100)$ \\
\hline
\end{tabular}

Table 2 shows that $29 \%$ of the nurses who had WMSDs were between 30 to 39 years, $40.1 \%$ of the female nurses had WMSDs in comparison to male nurses (26.7\%). More than half $(56.5 \%)$ of the study sample who had WMSDs were married in comparison to $10.3 \%$ who were single. The highest percentage $(37.4 \%)$ of the nurses who had WMSDs had graduated from the Institute of Nursing of the nurses, who had WMSDs $60.3 \%$ were non-smoker; more than a additional job, and $55.3 \%$ were not participated in any training toward preventing WMSDs.

\section{DISCUSSION}

The data finding shown in figure (1) identifies that during the last twelve months, the prevalence of work-related musculoskeletal disorders (WMSDs) among nurses in Erbil teaching hospitals in this study was $66.8 \%$. This finding is in line 
Table 2: Association between socio-demographic characteristics of the nurses and WMSDs

\begin{tabular}{|c|c|c|c|c|}
\hline \multirow{3}{*}{ Variable } & \multicolumn{2}{|c|}{ WMSDs } & \multirow[b]{2}{*}{ Total } & \multirow{3}{*}{ P-value } \\
\hline & Yes & No & & \\
\hline & F $(\%)$ & F $(\%)$ & $\mathbf{F}(\%)$ & \\
\hline \multicolumn{5}{|l|}{ Age groups } \\
\hline $20-29$ & $41(15.6)$ & $28(10.7)$ & $69(26.3)$ & \multirow{4}{*}{0.13} \\
\hline $30-39$ & $76(29)$ & $34(13)$ & $110(42)$ & \\
\hline $40-49$ & $34(13)$ & $20(7.6)$ & $54(20.6)$ & \\
\hline $50-59$ & $24(9.2)$ & $5(1.9)$ & $29(11.1)$ & \\
\hline \multicolumn{5}{|l|}{ Gender } \\
\hline Male & $70(26.7)$ & $60(22.9)$ & $130(49.6)$ & \multirow{2}{*}{$<0.001$} \\
\hline Female & $105(40.1)$ & $27(10.3)$ & $132(50.4)$ & \\
\hline \multicolumn{5}{|l|}{ Marital Status } \\
\hline Single & $27(10.3)$ & $22(8.4)$ & 49 (18.7) & \multirow{2}{*}{0.05} \\
\hline Married & $148(56.5)$ & $65(24.8)$ & $213(81.3)$ & \\
\hline \multicolumn{5}{|l|}{ Educational Level } \\
\hline School nursing & $13(5)$ & $1(0.4)$ & $14(5.4)$ & \multirow{5}{*}{0.23} \\
\hline Preparatory nursing & $41(15.6)$ & $18(6.9)$ & $59(22.5)$ & \\
\hline Institutional nursing & $98(37.4)$ & $53(20.2)$ & $151(57.6)$ & \\
\hline College of nursing & $22(8.4)$ & $14(5.3)$ & $36(13.7)$ & \\
\hline Post graduate nursing & $1(0.4)$ & $1(0.4)$ & $2(0.8)$ & \\
\hline \multicolumn{5}{|l|}{ Smoking Status } \\
\hline Yes & $17(6.5)$ & $12(4.6)$ & $29(11.1)$ & \multirow{2}{*}{0.32} \\
\hline No & $158(60.3)$ & $75(28.6)$ & $233(88.9)$ & \\
\hline \multicolumn{5}{|l|}{ BMI (Weight Status) } \\
\hline$<18.5$ (Underweight) & $52(19.9)$ & $27(10.3)$ & $79(30.2)$ & \multirow{4}{*}{0.21} \\
\hline 18.5-24.9 (Normal) & $43(16.4)$ & $12(4.6)$ & $55(21)$ & \\
\hline 25-29.9 (Overweight) & $75(28.6)$ & $44(16.8)$ & $119(45.4)$ & \\
\hline 30-39.9 (Obesity) & $5(1.9)$ & $4(1.5)$ & $9(3.4)$ & \\
\hline \multicolumn{5}{|l|}{ Physical Exercise } \\
\hline Yes & $57(21.8)$ & $29(11)$ & $86(32.8)$ & \multirow{3}{*}{0.90} \\
\hline No & $118(45)$ & $58(22.2)$ & $176(67.2)$ & \\
\hline Total & $175(66.8)$ & $87(33.2)$ & $262(100)$ & \\
\hline
\end{tabular}

with the results of a study done in Ethekwini/South Africa, when the researchers reported that the twelve months prevalence of WMSDs among the nurses was also $67 \%,[10]$, and also similar to one done in Zambia (68.9\%),[11]. However, the current study's result is higher than those observed in Canada (61\%) [12], and the
United States (60\%) [13]. The rate was lower than that in what was reported among nurses in Brazil which was 93\%[14], among Turkish nurses 90\%[15], and among Iranian nurses was $89.9 \%[16]$. The reason behind the different prevalence rate of WMSDs in different countries/hospitals might be the differences in psychological and physical 
Table 3: Association between work-related factors with MSDs among nurses

\begin{tabular}{|c|c|c|c|c|}
\hline \multirow{3}{*}{ Variable } & \multicolumn{2}{|c|}{ WMSDs } & \multirow[b]{2}{*}{ Total } & \multirow{3}{*}{ P-value } \\
\hline & Yes & No & & \\
\hline & F (\%) & F (\%) & F (\%) & \\
\hline \multicolumn{5}{|l|}{ Years of Experience } \\
\hline $1-10$ & $83(31.7)$ & $45(17.2)$ & $128(48.9)$ & \multirow{5}{*}{0.02} \\
\hline $11-20$ & $43(16.4)$ & $31(11.8)$ & $74(28.2)$ & \\
\hline $21-30$ & $36(13.7)$ & $11(4.2)$ & 47 (17.9) & \\
\hline $31-40$ & $10(3.8)$ & $0(0)$ & $10(3.8)$ & \\
\hline $41-50$ & $3(1.1)$ & $0(0)$ & $3(1.1)$ & \\
\hline \multicolumn{5}{|l|}{ Unit/ Ward } \\
\hline Catheterization & $3(1.1)$ & $2(0.8)$ & $5(1.9)$ & \multirow{9}{*}{0.7} \\
\hline Consultation & $12(4.6)$ & $8(3.1)$ & $20(7.6)$ & \\
\hline Delivery unit & $11(4.2)$ & $2(0.8)$ & $13(5)$ & \\
\hline Emergency & $16(6.1)$ & $7(2.7)$ & $23(8.8)$ & \\
\hline $\mathrm{ICU}$ & $29(11.1)$ & $15(5.7)$ & $44(16.8)$ & \\
\hline Medical & $24(9.2)$ & $7(2.7)$ & $31(11.8)$ & \\
\hline NICU & $6(2.3)$ & $3(1.1)$ & $9(3.4)$ & \\
\hline Surgical & $52(19.8)$ & $27(10.3)$ & $79(30.2)$ & \\
\hline Theatre & $22(8.4)$ & $16(6.1)$ & $38(14.5)$ & \\
\hline \multicolumn{5}{|l|}{ Dual Employment } \\
\hline Yes & $46(17.6)$ & $42(16)$ & $88(33.6)$ & \multirow{2}{*}{$<0.001$} \\
\hline No & $129(49.2)$ & $45(17.2)$ & $174(66.4)$ & \\
\hline \multicolumn{5}{|l|}{ Participation in training } \\
\hline Yes & $30(11.5)$ & $25(9.5)$ & $55(21)$ & \multirow{3}{*}{0.03} \\
\hline No & $145(55.3)$ & $62(23.7)$ & 207 (79) & \\
\hline Total & $175(66.8)$ & $87(33.2)$ & $262(100)$ & \\
\hline
\end{tabular}

\section{DISCUSSION}

environments. Firstly, some hospitals have implemented the policy of "minimal manual lift" and use of devices to change the position of patients which helped to reduce the risk of musculoskeletal disorders [17]. Secondly, the difference in the results may be related to sociodemographic characteristics, the range of disease conditions, work characteristics, job factors, practice settings, number of study participants, the availability of basic equipment, and the regular participation of the nurses in strategic training programs programs toward preventing of WMSDs. Many previous studies focused on several body regions due to the tendency of WMSDs affecting more than two body parts. The current study sought to compare the prevalence of WMSDs in all nine body regions, identified by the Nordic questionnaire for musculoskeletal symptoms [9]. The current study revealed that the lower back disorder at $75 \%$ was the most prevalent region compared to other body regions followed by one or both knees at $52 \%$, Low back pain was the more prevalent on all units and across all nurse ranks, which was agreed with the several 
previous studies. In addition, low back pain was the most prevalent body region in most of the previous studies. [18]. The present study shows that the most nurses with WMSDs were those in their third decade of age, and there was no significant association between age categories and prevalence of WMSDs ( $p$-value $=0.130$ ). The current study is in agreement with the findings of [19], that there is no significant relationship between age and prevalence of WMSDs within this population at ( $p$-value 0.05 ) and it is also agreed with the reports of a study done among nurses in Zambia [20]. The current study shows that $55.3 \%$ of the nurses who had WMSDs were not participated in any training toward preventing injuries in comparison to only $11.5 \%$ of the nurses who also had WMSDs but they were participated in training programs. This finding indicates that participation in training programs toward preventing WMSDs by nurses may be a factor to decrease WMSDs.The table also shows that there is a significant relationship between the prevalence of WMSDs among participant nurses and their participation in training toward prevent WMSDs at ( $p$ value $=0.03$ )

\section{CONCLUSION}

The twelve months time period of WMSDs in this study was $67 \%$. Lower back disorder Demographic factors such as age, marital status, educational level, body mass index, smoking, and physical exercise performance did not predispose to an increase in the prevalence of WMSDs. But some demographic factors such as gender were found have a strong relationship with the prevalence of WMSDs.The prevalence of WMSDs is higher among nurses who were not participated in any training strategies to prevent work-related musculoskeletal disorders (70\%), and it found that there was a strong relationship between prevalence of WMSDs and training.

\section{CONFLICTS OF INTEREST}

The authors reported no conflicts of interest.

\section{REFERENCES}

[1] National Institute for Occupational Safety and Health. Musculoskeletal disorders and workplace factors: a critical review of epidemiologic evidence for workrelated musculoskeletal disorders of the neck, upper extremity, and low back. Cincinnati (OH). (DHHS (NIOSH) Publication No.(97B141) 1997

[2] Ministry of Health, Repetitive Strain Injury (RSI), Work -Related Musculoskeletal Disorders (MSDs), Pain related to work. Protocols of comprehensive health care of different complexity worker, Brasilia: Ministry of Health, 2006.

[3] Harcombe H, Herbison GP, McBride D, Derrett S. Musculoskeletal disorders among nurses compared with two other occupational groups. Occup Med; 2014, 64: 601-7.

[4] Punnett L, Wegman DH. Work-related musculoskeletal disorders: the epidemiologic evidence and the debate. J ElectromyogrKinesiol,2004, 14:13-23.

[5] Ando S, Ono Y, Shimaoka M, Hiruta S, Hattovi Y, Hori $F$, et al. Association of self- estimated workloads with musculoskeletal symptoms hospital nurses. Occup Environ Med, 2000, 57: 211.

[6] da Costa BR, Vieira ER. Risk factors for work-related musculoskeletal disorders: A systematic review of recent longitudinalstudies. Am J. Ind Med. 2010;53 (3):285-323.

[7] Lorusso A, Bruno S, L'Abbate N. Musculoskeletal complaints among Italian X-ray technologists, Ind Health, 2007,45, 705-8

[8] Hildebrandt VH, Bongers PM,Dul J, Dijk FJHV, Kemper HCG, The relationship between leisure time, physical activities and musculoskeletal symptoms and disability in worker populations. Int Arch Occup Environ Health, 2000, 73:507-18.

[9] Kuorinka, L., Jonsson, B., Kilbom, A., Vinterberg, H., Biering-Sorensen, F., Anderson, G. et al. Standardised Nordic questionnaires for the analysis of musculoskeletal symptoms,ApplErgon, 1987, 18 (3): 233-7.

[10] BabusisiweThandi Evan Kumalo, The relationship between work-related musculoskeletal disorders, absenteeism and visits to the staff clinic by nurses in an Ethekwini district hospital, Durban University of Technology,2014,Available:http://ir.dut.ac.za/ handle $/ 10321 / 1255$ ?show=full.

[11] Loveness A. Nkhata1, Tonya M. Esterhuizen1, Seter Siziya, Peter D. C. Phiri, Esther Munalula-Nkandu, Hastings Shula. The Prevalence and Perceived Contributing Factors for Work-Related Musculoskeletal Disorders among Nurses at the University Teaching Hospital in Lusaka, Zambia. sjph, 2015, 3(4): 508-513. Available: http://www.sciencepublishinggroup.com/ journal/paperinfo.aspx?journalid 
[12] Yassi A, Gilbert M, Cvitkovich Y. Trends in injuries, illnesses, and policies in Canadian healthcare workplaces, Can J Public Health, 2005, 96:333-9. Available:http://www.ncbi.nlm.nih.gov/ pubmed/16238148.

[13] Trinkoff, A. M., Lipscomb, J. A., Geiger-Brown, J., \& Brady, B. Musculoskeletal problems of the neck, shoulder and back and functional consequences in nurses,Am J Ind Med, 2002, 41, 170-8 Available:http://www.ncbi.nlm.nih.gov/ pubmed/11920961.

[14] Gurgueira GP, Alexandre NM, CorrêaFilho HR: Selfreported musculoskeletal symptoms among nursing personnel. Rev Lat Am Enfermagem 2003, 11:608613.Avaiilable:http://bmcresnotes.biomedcentral. com /arti les/10.1186/1756-0500-7-61.

[15] Tezel A. Musculoskeletal complaints among a group of Turkish nurses, Int J Neurosc,2005, 115:871-80 Available:http://www.ncbi.nlm.nih.gov/ pubmed/16019580.

[16] Barzideh M, ChoobinehA, and TabatabaeiS. Job stress dimensions and their relationship to MSDs among Iranian nurses. J. Health System Research, 2012, Volume 8, Number 7,1365-75.Available:http://en. journals.sid.ir/ViewPaper.aspx?ID=348732.

[17] Lusted MJ, Carrasco CL, Mandryk JA and Healey S. Self-reported symptoms in the neck and upper limbs in nurses. Applied ergonomics, 1996, 27(6):381-7

[18] Sheikhzadeh A, Gore C, Zuckerman JD, Nordin M. 2009. Perioperating nurses and technicians' perceptions of ergonomic risk factors in the surgical environment, Appl Ergon. 40:833-9. Available: http:// www.ncbi.nlm.nih.gov/pubmed/19027099.

[19] Altman, J.R. 2010. Neck and shoulder pain in nurses working in seven wards of Tygerberg hospital: Quantifying the problem and exploring the risks (online). M. Science, Stellenbosch University. Available: http://www.scholar.sun.ac.za/bitstream/ handle/10019.

[20] Loveness A. Nkhata1, Tonya M. Esterhuizen1, Seter Siziya, Peter D. C. Phiri, Esther Munalula-Nkandu, Hastings Shula. 2015. The Prevalence and Perceived Contributing Factors for Work-Related Musculoskeletal Disorders among Nurses at the University Teaching Hospital in Lusaka, Zambia. Science Journal of Public Health. 3(4): 508-13. Available: http:// www.sciencepublishinggroup.com/journal/ paperinfo.aspx?journalid=. 